\title{
Systemic Lupus Erythematosus Accompanied by Psoriasis Induces IL-27-Producing Cells in Both Affected Areas of the Skin
}

\author{
Gen-ichi Tojo Taku Fujimura Yumi Kambayashi \\ Setsuya Aiba \\ Department of Dermatology, Tohoku University Graduate School of Medicine, \\ Sendai, Japan
}

\section{Key Words}

IL-27 - Activated antigen-presenting cells · Type 1 helper T cells

\begin{abstract}
IL-27 is mainly produced by activated antigen-presenting cells (APCs), and has been reported in various Th1/Th17-mediated inflammatory diseases, including psoriasis, and even in Th2complexed disease, such as systemic lupus erythematosus (SLE). We describe a 51-year-old Japanese man with SLE accompanied by psoriasis. Interestingly, immunohistochemical staining revealed the existence of IL-27-producing cells in biopsy specimens from both SLE and psoriasis. Our findings might suggest relationships between IL-27 and the pathogenesis of these inflammatory diseases.
\end{abstract}

\section{Introduction}

IL-27, a member of the IL-12 family, is composed of EBI3 and p28 subunits and activates both STAT1 and STAT3 through a distinct IL-27 receptor, which consists of the unique receptor subunit WSX-1 paired with the gp130 chain [1]. IL-27 is mainly produced by activated antigen-presenting cells (APCs) and is involved in priming T helper 1 (Th1) cells [1-3]. Recently, IL-27 has been reported in various Th1/Th17mediated inflammatory diseases including psoriasis [3], and even in Th2-complexed disease, such as systemic lupus erythematosus (SLE) [4, 5]. In this report, we describe a case of SLE accompanied by psoriasis. Interestingly, biopsy specimens from areas involved by both of these disorders included IL-27-producing cells in the superficial 
dermis, which might suggest a relationship between IL-27 and the pathogenesis of SLE accompanied with psoriasis.

\section{Case Report}

A 51-year-old Japanese man visited our outpatient clinic with a three-year history of asymptomatic erythema on his extremities. After the eruption appeared, he had repeated episodes of fever, general fatigue, and pain on his fingers. On his initial visit, physical examination revealed dark, infiltrated erythemas on his cheek, trunk and extremities (fig. 1a). A biopsy specimen revealed hydropic degeneration of the basal cell layer with band-like infiltration of leukocytes and extravasation of erythrocytes ( $\underline{\text { fig. } 2}$ a). A full blood count and biochemical profile revealed increased levels of ANA $(\times 1,280)$ and anti-dsDNA antibodies $(26.1 \mathrm{U} / \mathrm{ml})$, and prominent decrease of white blood cells $(2,500 / \mu \mathrm{l})$, platelets $(116,000 / \mu \mathrm{l})$ and red blood cells $\left(2.74 \times 10^{4} / \mu \mathrm{l}\right)$. From the above findings, and according to the American College of Rheumatology (ACR) SLE classification criteria [13, 14], we diagnosed this patient as SLE. We treated him with oral prednisolone $40 \mathrm{mg} /$ day and all eruptions and symptoms disappeared. One month after the initial eruptions disappeared, red scaly, sharply demarcated plaques appeared on his back (fig. 1b). The biopsy specimen revealed markedly elongated rete ridges, parakeratosis with neutrophils and dilated tortuous vessels in the dermal papillae (fig. 2b). We diagnosed this eruption as psoriasis accompanied by SLE. To further investigate the relationship between SLE and psoriasis, we employed immunohistochemical staining for IL-27. Immunohistochemical staining revealed IL-27-positive cells in specimens from areas involved by both SLE and psoriasis. In the SLE specimen, we detected IL-27-positive cells in superficial dermal areas (fig. 2c), while in the psoriasis specimen, we detected IL-27-positive cells mainly in dermal papillae (fig. 2d). In addition, the double staining for IL-27 with HLA-DR revealed that these IL-27 producing cells were HLA-DR+ cells (online suppl. data, see www.karger.com/doi/10.1159/000342803).

\section{Discussion}

SLE is a prototypical autoimmune disease that shows a wide range of manifestations, such as glomerulonephritis, arthritis and skin inflammation. Previous reports described that SLE is a complex disease driven by different lymphocyte subsets (e.g. Th1, Th2, Th17, and Tregs) with high heterogeneity in the clinical manifestations and organ involvement [5]. Among them, Kido et al. [4] reported the significance of IL-27 in the pathogenesis of SLE. They concluded that IL-27/WSX-1 signaling may play a protective role in the development of SLE-like skin inflammation, and modulating IL-27/WSX-1 signaling might be an interesting therapeutic strategy in the treatment of SLE [4].

Psoriasis is a cutaneous disorder characterized by epidermal hyperproliferation and inflammation, and was previously considered to be mediated by Th1 cells. Recently, several studies suggested that other proinflammatory cytokine-producing cells, such as Th17, play a crucial role in the pathogenesis of psoriasis. More recently, Shibata et al. [3] reported the significance of IL-27 in the pathogenesis of psoriasis. They demonstrated that the higher serum IL-27 levels in psoriatic patients were correlated with the disease severity. In addition, they detected IL-27-secreting cells in the papillary dermis of psoriatic skin lesions. In aggregate, they concluded that IL-27 might promote the onset of psoriasis [3].

Coincident SLE and psoriasis is relatively rare. Previously, Zalla and Muller [11] reported that $1.1 \%$ of LE patients had coexisting psoriasis. Among them, the major subpopulation of LE was SLE (45\%), and 10/19 patients developed psoriasis first and the others first developed SLE [11]. More recently, Vereecke et al. reported that 
polymorphisms within the A20 [also known as TNFAIP3 (tumor necrosis factor $\alpha$ induced protein 3)] genomic locus have been associated with both SLE and psoriasis [12]. In aggregate, though several previous reports suggested the possible factors for coincidence of SLE and psoriasis, the immunological background is poorly understood. Therefore, in the present report, we employed immunohistochemical staining for IL-27.

IL-27 is produced by activated APCs and induces the proliferation and expression of T-bet in naive CD4+ T cells [6, 7]. WSX-1, which was cloned as a homologue of gp130 of the IL-6 receptor, constitutes a functional, signal-transducing receptor for IL-27 with gp130. WSX-1 is highly expressed in CD4+ T cells, NK cells, NKT cells and macrophages [8]. In T lymphocytes, IL-27 induces STAT1 and STAT3 activation, thus resulting in the enhancement of naive CD4 T-cell proliferation, the promotion of early Th1 differentiation, and the suppression of the differentiation of Th2 and Th17 cells [2]. In addition, it is also reported that IL-27 plays a key role in generating IL-10-producing regulatory $\mathrm{T}$ cells $[2,9]$. Indeed, previously, we detected Foxp3-positive regulatory $\mathrm{T}$ cells in the papillary dermis of psoriatic skin [10]. Our previous report also might suggest the possible significance of IL-27 in the pathogenesis of psoriasis. In this report, we present a case of SLE accompanied by psoriasis. Interestingly, both types of skin lesions contained IL-27-producing cells in the dermis. These findings might suggest relationships between IL-27 and the pathogenesis of SLE accompanied by psoriasis.
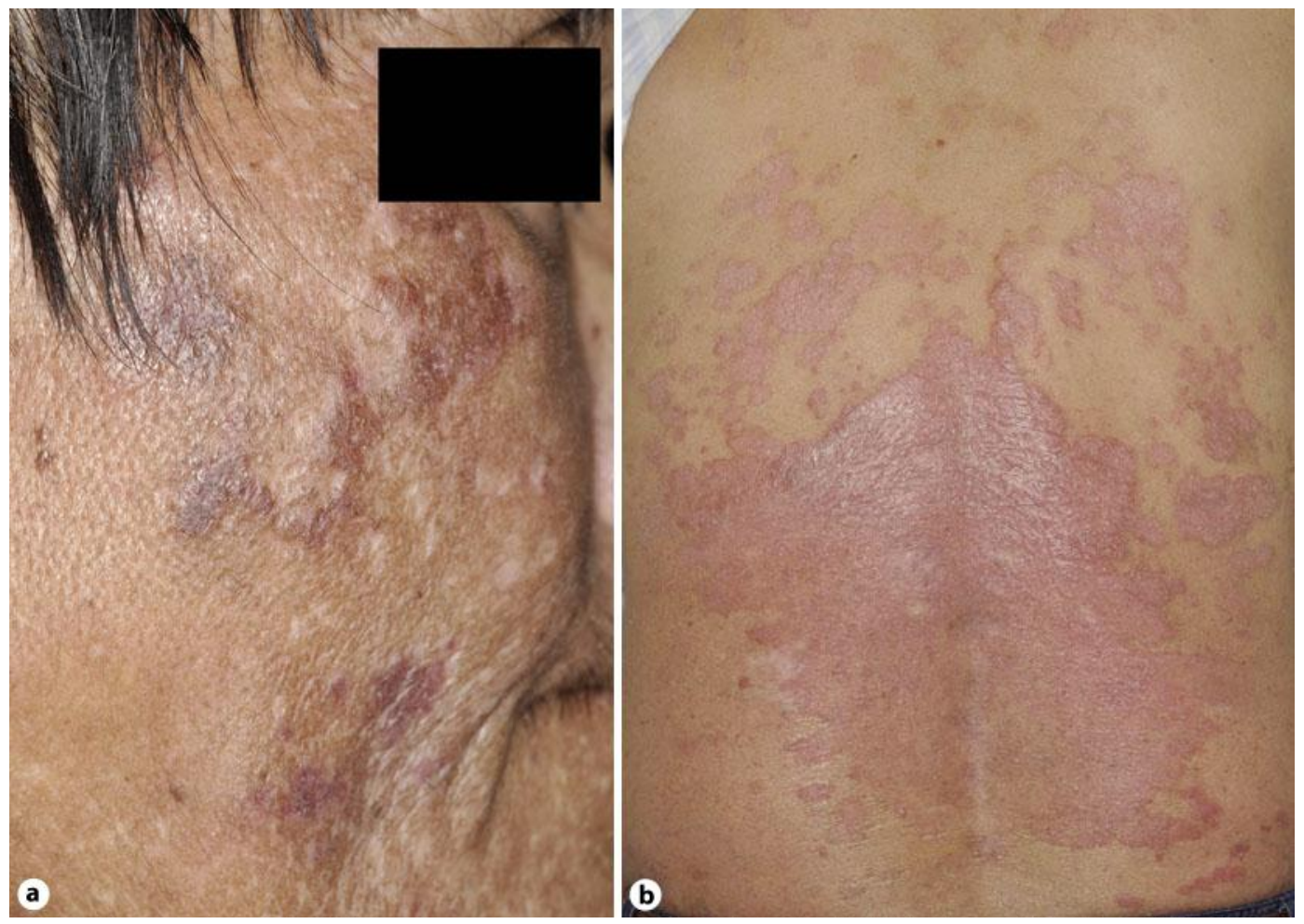

Fig. 1. Dark, infiltrated erythemas on the cheek (a). Red scaly, sharply demarcated plaques on the back (b). 

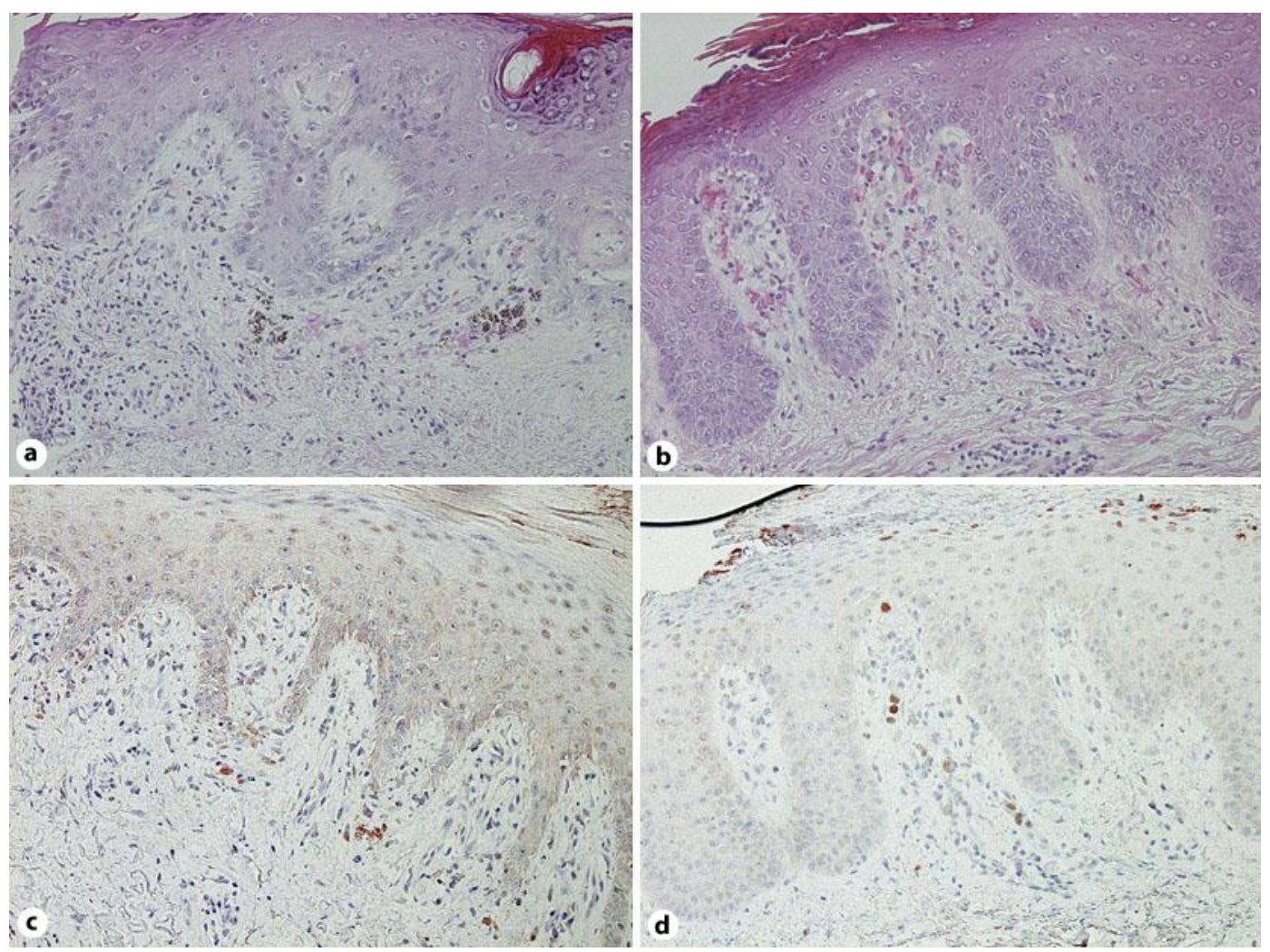

Fig. 2. Hydropic degeneration of the basal cell layer with band-like infiltration of leukocytes and extravasation of erythrocytes (a). Markedly elongated rete ridges, parakeratosis with neutrophils and dilated tortuous vessels in the dermal papillae (b). Immunohistochemistry for IL-27; paraffinembedded tissue samples from patients with SLE (c) and psoriasis (d) were deparaffinized and stained using anti-IL-27 Ab (a-d). Original magnification $\times 200$.

\section{References}

-1 Pflanz S, Hibbert L, Mattson J, Rosales R, Vaisberg E, Bazan JF, Phillips JH, McClanahan TK, de Waal Malefyt R, Kastelein RA: WSX-1 and glycoprotein 130 constitute a signal-transducing receptor for IL-27. J Immunol 2004;172:2225-2231.

-2 Trinchieri G, Pflanz S, Kastelein RA: The IL-12 family of heterodimeric cytokines: new players in the regulation of T cell responses. Immunity 2003;19:641-644.

-3 Shibata S, Tada Y, Kanda N, Nashiro K, Kamata M, Karakawa M, Miyagaki T, Kai H, Saeki H, Shirakata Y, Watanabe S, Tamaki K, Sato S: Possible roles of IL-27 in the pathogenesis of psoriasis. J Invest Dermatol 2010;130:1034-1039.

4 Kido M, Takeuchi S, Sugiyama N, Esaki H, Nakashima H, Yoshida H, Furue M: T cell-specific overexpression of interleukin-27 receptor $\alpha$ subunit (WSX-1) prevents spontaneous skin inflammation in MRL/lpr mice. Br J Dermatol 2011;164:1214-1220.

5 Miyake K, Akahoshi M, Nakashima H: Th subset balance in lupus nephritis. J Biomed Biotech 2011;2011:980286.

6 Pflanz S, Timans JC, Cheung J, Rosales R, Kanzler H, Gilbert J, Hibbert L, Churakova T, Travis M, Vaisberg E, Blumenschein WM, Mattson JD, Wagner JL, To W, Zurawski S, McClanahan TK, Gorman DM, Bazan JF, de Waal Malefyt R, Rennick D, Kastelein RA: IL-27, a heterodimeric cytokine composed of EBI3 and p28 protein, induces proliferation of naive CD4(+) T cells. Immunity 2002;16:779-790. 
-7 Takeda A, Hamano S, Yamanaka A, Hanada T, Ishibashi T, Mak TW, Yoshimura A, Yoshida H: Cutting edge: role of IL-27/WSX-1 signaling for induction of T-bet through activation of STAT1 during initial Th1 commitment. J Immunol 2003;170:4886-4890.

-8 Sugiyama N, Nakashima H, Yoshimura T, Sadanaga A, Shimizu S, Masutani K, Igawa T, Akahoshi M, Miyake K, Takeda A, Yoshimura A, Hamano S, Yoshida H: Amelioration of human lupus-like phenotypes in MRL/lpr mice by overexpression of interleukin 27 receptor alpha (WSX-1). Ann Rheum Dis 2008;67:1461-1467.

9 Xu M, Mizoguchi I, Morishima N, Chiba Y, Mizuguchi J, Yoshimoto T: Regulation of antitumor immune responses by the IL-12 family cytokines. IL-12, IL-23, and IL-27. Clin Dev Immunol 2010;pii:832454.

$\checkmark 10$ Fujimura T, Okuyama R, Ito Y, Aiba S: Profiles of Foxp3+ regulatory T cells in eczematous dermatitis, psoriasis vulgaris and mycosis fungoides. Br J Dermatol 2008;158:1256-1263.

11 Zalla MJ, Muller SA: The coexistence of psoriasis with lupus erythematosus and other photosensitive disorders. Acta Derm Venereol Suppl (Stockh) 1996;195:1-15.

12 Vereecke L, Beyaert R, van Loo G: Genetic relationships between A20/TNFAIP3, chronic inflammation and autoimmune disease. Biochem Soc Trans 2011;39:1086-1091.

13 Petri M, Orbai AM, Alarcón GS, Gordon C, Merrill JT, Fortin PR, Bruce IN, Isenberg D, Wallace DJ, Nived O, Sturfelt G, Ramsey-Goldman R, Bae SC, Hanly JG, Sánchez-Guerrero J, Clarke A, Aranow C, Manzi S, Urowitz M, Gladman D, Kalunian K, Costner M, Werth VP, Zoma A, Bernatsky S, Ruiz-Irastorza G, Khamashta MA, Jacobsen S, Buyon JP, Maddison P, Dooley MA, van Vollenhoven RF, Ginzler E, Stoll T, Peschken C, Jorizzo JL, Callen JP, Lim SS, Fessler BJ, Inanc M, Kamen DL, Rahman A, Steinsson K, Franks AG Jr, Sigler L, Hameed S, Fang H, Pham N, Brey R, Weisman MH, McGwin G Jr, Magder LS: Derivation and validation of the Systemic Lupus International Collaborating Clinics classification criteria for systemic lupus erythematosus. Arthritis Rheum 2012;64:2677-2686.

14 Tan EM, Cohen AS, Fries JF, Masi AT, McShane DJ, Rothfield NF, Schaller JG, Talal N, Winchester RJ: The 1982 revised criteria for the classification of systemic lupus erythematosus. Arthritis Rheum 1982;25:1271-1277. 